\title{
Rapid Py-GC/MS assessment of the structural alterations of lignins in genetically modified plants
}

Jorge Rencoret ${ }^{1, *}$, José Carlos del Río ${ }^{1}$, Klaas G.J. Nierop ${ }^{2}$, Ana Gutiérrez ${ }^{1}$ and John $\mathrm{Ralph}^{3}$

${ }^{1}$ Instituto de Recursos Naturales y Agrobiología de Sevilla, CSIC, 41012-Seville, Spain

${ }^{2}$ Department of Earth Sciences - Organic Geochemistry, Faculty of Geosciences,

Utrecht University, 3584 CS, Utrecht, The Netherlands

${ }^{3}$ Departments of Biochemistry and Biological Systems Engineering, and the DOE Great

Lakes Bioenergy Research Center, the Wisconsin Energy Institute, University of

Wisconsin, Madison, Wisconsin 53726, USA

* Corresponding author: (Tel: +34 954624711; Fax : +34 954624002; E-mail: jrencoret@irnase.csic.es) 


\begin{abstract}
Genetic modifications for perturbing the lignin pathway in three different species of angiosperm plants, including non-woody (Arabidopsis and alfalfa) and woody (poplar) plants, were readily evaluated by analytical pyrolysis coupled to gas chromatography-mass spectrometry (Py-GC/MS). Pyrolysis showed that the composition of Arabidopsis plants was severely altered when the expression of the gene encoding the enzyme caffeic acid $O$-methyltransferase (COMT) was downregulated, resulting in a lignin largely enriched in guaiacyl (G) units (88\%). Alfalfa plants in which lignin biosynthesis was modified by down-regulation of the p-coumarate 3-hydroxylase $(\mathrm{C} 3 \mathrm{H})$ gene, showed extremely high proportions of $p$ hydroxyphenyl $(\mathrm{H})$ units $(71 \%)$ relative to the naturally prevailing guaiacyl $(\mathrm{G})$ and syringyl (S) units. Finally, Py-GC/MS analyses indicated that overexpression in poplar of the gene that encodes the enzyme ferulate 5-hydroxylase (F5H) resulted in a lignin with a higher content of syringyl lignin units $(88 \%)$ compared to the wild-type control (71\%). In conclusion, Py-GC/MS is a useful and convenient tool for the rapid evaluation of compositional changes in lignin from genetically modified plants.
\end{abstract}

Key words: Pyrolysis; lignin; whole cell-walls; transgenic plants; woody; non-woody. 


\section{Introduction}

Lignin is a complex aromatic biopolymer characteristic of vascular plants, where it provides mechanical support, waterproofs the cell-wall, and protects plants against microbial attack, limiting polysaccharide hydrolysis. Lignin acts as a biological cement between cellulose and hemicelluloses in the secondary cell wall and is the main cause of lignocellulosic biomass recalcitrance to efficient utilization of lignocellulosic substrates. Due to the negative processing effects of the presence of lignin in cell walls, there have been numerous efforts towards engineering lignin biosynthesis to produce plants with lower lignin content or with a lignin structure more amenable to chemical degradation [1]. In this context, a promising approach is to develop genetically modified plants by up- and down-regulating the expression of key genes involved in the biosynthesis of the lignin precursors (Figure 1). Lignin derives mainly from the oxidative coupling of three $p$-hydroxycinnamyl alcohol monomers, $p$-coumaryl, coniferyl and sinapyl alcohols that produce respectively the $p$-hydroxyphenyl $(\mathrm{H})$, guaiacyl $(\mathrm{G})$ and syringyl (S) phenylpropanoid units when incorporated into the lignin polymer [2]. The lignin content as well as the monomer composition and inter-unit linkage distribution are widely variable between species and tissues. In general terms, gymnosperm lignins are composed of G- units with minor amounts of H-units, woody and non-woody angiosperm lignins are G-S lignins with variable $\mathrm{S}: \mathrm{G}$ ratios, whereas grasses contain all the three units, although the levels of H-units have often been over-attributed [3]. Substantial compositional changes in angiosperm lignins can be obtained from misregulation of single genes in the lignin biosynthetic pathway, with the aim of altering the ratio of the three principal lignin monomers or monolignols $[2,4,5]$. The lignin of any plant can, in principle, be engineered and altered to produce more desirable lignin polymers thanks to the flexibility of the lignification mechanism that, 
unlike of other biopolymers such as cellulose and hemicelluloses, does not follow any structural pattern [6]. In this sense, plants can use any and all of the synthesized monolignols, regardless of the proportion in which they are produced, as long as they are transported to the lignification zone. Among the most impressive genetically modified plants are transgenic hybrid poplar trees with elevated levels of the enzyme ferulate 5-hydroxylase $(\mathrm{F} 5 \mathrm{H})$ that produce lignins highly enriched in syringyl units, enhance biomass conversion [7,8] and are more resistant to fungal attack [9]; alfalfa plants with improved digestibility derived from increasing the amounts of $\mathrm{H}$ lignin units (over $90 \%$ ) by downregulation of the gene that encodes the enzyme $p$-coumarate 3 hydroxylase $(\mathrm{C} 3 \mathrm{H})$ [10]; and Arabidopsis plants that do not produce $\mathrm{S}$ lignin, but generate 5-hydroxy-guaiacyl (5OHG) units as well as the usual $\mathrm{G}$ units by downregulation of the gene encoding the enzyme caffeic acid $O$-methyltransferase (COMT).

In order to assess the changes produced in the lignin composition (H:G:S) as result of modifying the expression of genes involved in monolignol biosynthesis, it is important to have appropriate analytical tools that can be used for quick screening as well as for detailed structural analysis. Nowadays, there are several analytical techniques and methodologies that can provide valuable information about the composition of lignin, including spectroscopic methods such as FT-IR [11] or nuclear magnetic resonance (NMR) [12], chemical degradative methods such as permanganate and nitrobenzene oxidations [13,14], and thioacidolysis [15] or derivatization followed by reductive cleavage (DFRC) [16]. However, these methods often require tedious and timeconsuming procedures and need significant amounts of plant sample, which sometimes is a major limitation in plant genetic engineering. In this context, analytical pyrolysis coupled to gas chromatography and mass spectrometry (Py-GC/MS) is a rapid and 
highly sensitive analytical tool that allows the analysis of very small amounts of sample without any prior manipulation and/or isolation. Pyrolysis offers some important advantages that include: i) easy sample preparation; ii) small sample amount requirement (less than $1 \mathrm{mg}$, typically $\sim 100 \mu \mathrm{g}$ ); iii) short analysis times (20-30 min); iv) allows for direct in situ analysis of the lignin polymer, i.e., without requiring prior lignin isolation, and v) high sensitivity. Py-GC/MS has already proven to be a reliable analytical technique for the rapid characterization of lignins from many different wildtype plants, including both woody and non-woody varieties [17-23]. It is also an excellent tool to analyze the variations in the lignin composition of genetically modified plants [24-29]. In addition, Py-GC/MS analysis can be applied to young plants without requiring destructive sampling, as it only needs a minimal amount of sample. Given its moderate throughput and easy sampling method, it is a useful procedure to assess the alterations produced in the lignin polymer of a large number of genetically modified plants. In the present work, the value of Py-GC/MS analysis for revealing the key features of three genetically modified plants including $\mathrm{C} 3 \mathrm{H}$-downregulated alfalfa, an Arabidopsis comt mutant, and an $\mathrm{F} 5 \mathrm{H}$-upregulated poplar, is presented.

\section{Material and methods}

\subsection{Plant materials}

The samples used in the present work consisted of woody (poplar) and non-woody (Arabidopsis and alfalfa) angiosperms, including wild-type controls and their respective genetically modified lines used in previous studies.

Wild-type, comt-deficient and comt C4H:F5H1 chs Arabidopsis 
The Arabidopsis lines, Columbia (Col-0) were from an earlier study [30]. The comt mutant (At5g54160, SALK_002373) was obtained from the SALK collection. To obtain the comt $C 4 H: F 5 H 1$ chs mutant, a chalcone synthase (chs) mutation was crossed into a comt C4H:F5H1 background. Plants were germinated directly in Saniflor soil (Van Israel; http://vanisrael.testvds.com) supplemented with $10 \% \mathrm{v} / \mathrm{v}$ vermiculite (16 h light, $22{ }^{\circ} \mathrm{C}, 55 \%$ humidity). Senesced inflorescence stems of Arabidopsis were ground in a Retsch MM400 mixer mill, equipped with a $10 \mathrm{~mL} \mathrm{ZrO}_{2}$ vessel and $\mathrm{ZrO}_{2}$ ball-bearings (2x12 mm diameter), for $1 \mathrm{~min}$ at $30 \mathrm{~Hz}$, for subsequent analysis.

Wild-type and C3H-deficient alfalfa

Wild-type and transgenic alfalfa (Medicago sativa cv. Regen SY) plants down-regulated in $\mathrm{C} 3 \mathrm{H}$ transcripts, having $\sim 5 \%$ residual $\mathrm{C} 3 \mathrm{H}$ activity, were from material described elsewhere [31]. Stems (internodes 4-10) were harvested from control (wt) and C3Hdeficient $(\mathrm{C} 3 \mathrm{H})$ alfalfa line, ground and Soxhlet-extracted sequentially with water, methanol, acetone, and chloroform. The isolated cell walls were ball-milled using a stainless steel jar containing stainless steel ball bearing $(5 \mathrm{~mm})$ for $2.5 \mathrm{~h}$, with $30 \mathrm{~min}$ breaks after every $30 \mathrm{~min}$ of milling to avoid excessive sample heating.

Wild-type and F5H-overexpressed poplar

F5H transgenic hybrid poplar (Populus tremula x Populus alba) was as previously described [8]. Both wild-type and the transgenic line were selected based on previous studies [7]. Stems were harvested from 2.5-year-old poplar wild-type and transgenic trees, manually debarked, and the pith was removed. Stems were ball milled using a 
Retsch PM100 mill at 600 rpm with $\mathrm{ZrO}_{2}$ jar $(50 \mathrm{~mL})$ and ball bearing $(3 \times 30 \mathrm{~mm}, 7 \times 10$ $\mathrm{mm}$ ), for $3 \mathrm{~h}$ (10 min breaks after every $20 \mathrm{~min}$ of milling).

\subsection{Pyrolysis-GC/MS}

Pyrolysis of samples $(\sim 100 \mu \mathrm{g})$ was performed with a 2020 microfurnace pyrolyzer (Frontier Laboratories Ltd.) connected to an Agilent 6890 GC-MS system equipped with a DB-1701 fused-silica capillary column $(30 \mathrm{~m} \times 0.25 \mathrm{~mm}$ i.d., $0.25 \mu \mathrm{m}$ film thickness) and an Agilent 5973 mass-selective detector (EI at $70 \mathrm{eV}$, mass range $\mathrm{m} / \mathrm{z}, 50$ 550, 2.89 scans/s). The pyrolysis was performed at $500{ }^{\circ} \mathrm{C}$ during $1 \mathrm{~min}$. The oven temperature was programmed from $50{ }^{\circ} \mathrm{C}(1 \mathrm{~min})$ to 100 at $20{ }^{\circ} \mathrm{C} \mathrm{min}^{-1}$ and then to 280 ${ }^{\circ} \mathrm{C}(5 \mathrm{~min})$ at $6{ }^{\circ} \mathrm{C} \mathrm{min}^{-1}$. Helium was the carrier gas $\left(1 \mathrm{~mL} \mathrm{~min}{ }^{-1}\right)$. The compounds were identified by comparing their mass spectra with those of the Wiley and NIST libraries and those reported in the literature $[20,21]$ and, when possible, by comparison with retention time and mass spectra of authentic standards. Peak molar areas were calculated for the lignin degradation products, the summed areas were normalized, and the data for two repetitive analyses were averaged and expressed as percentages. We report the compositional data on an $\mathrm{S}+\mathrm{G}+\mathrm{H}=100 \%$ basis. The relative standard deviation for the pyrolysis data was $<5 \%$.

Wild-type, COMT-deficient and comt C4H:F5H1 chs Arabidopsis were also analyzed on a Py-GC/MS instrument equipped with a Curie-Point pyrolyzer (Horizon Instruments) to confirm that 5-hydroxyguaiacol units can be released from benzodioxane structures that are characteristic of these lignins. Samples were pyrolyzed for $5 \mathrm{~s}$ at $600{ }^{\circ} \mathrm{C}$. The pyrolysis unit was connected to a Carlo Erba GC8060 gas chromatograph and the products were separated by a fused silica column (Varian, $25 \mathrm{~m}$, 
$0.32 \mathrm{~mm}$ i.d.) coated with CP-Sil5 (film thickness $0.40 \mu \mathrm{m}$ ). Helium was used as carrier gas. The oven was initially kept at $40{ }^{\circ} \mathrm{C}$ for $1 \mathrm{~min}$, next it was heated at a rate of $7{ }^{\circ} \mathrm{C}$ $\min ^{-1}$ to $320{ }^{\circ} \mathrm{C}$ and maintained at that temperature for $15 \mathrm{~min}$. The column was coupled to a Fisons MD800 mass spectrometer (mass range $\mathrm{m} / \mathrm{z}$ 45-650, ionization energy 70 $\mathrm{eV}$, cycle time $0.7 \mathrm{~s})$.

\section{Results and discussion}

The genetically modified plants selected for this study were COMT-deficient Arabidopsis [30], $C 3 H$-downregulated alfalfa [10], and $F 5 H$-overexpressed poplar [8]. The alterations produced in the lignin polymers in these genetically modified plants were analyzed by Py-GC/MS, and the results were compared to those from the respective wild-type plants (Figures 2-4). The identities and relative molar abundances of the compounds released upon pyrolysis from the plants analyzed are detailed in

Table 1. Significant differences were observed among the pyrograms of genetically modified plants compared to their respective wild-type controls, revealing important structural modifications produced in the lignin polymer as consequence of misregulating genes involved in the biosynthesis of monolignols.

\subsection{Wild-type and COMT-deficient Arabidopsis}

Caffeic acid $O$-methyltransferase (COMT) is an enzyme that methylates the 5-hydroxyl on the aromatic ring of monolignol precursors (Figure 1) and is therefore crucial for the biosynthesis of sinapyl alcohol and ultimately of syringyl groups in lignin. Previous studies have shown that COMT-deficient plants have a higher cell-wall degradability under both acid pretreatment and enzymatic digestion [32,33] but are generally much 
worse for pulping [34]. The pyrograms of the wild-type and the COMT-downregulated mutant Arabidopsis stems are shown in Figure $\mathbf{2}$ and the identities and relative molar abundances of the released compounds are listed in Table 1. Remarkable differences could be observed among them. Pyrolysis of the stem from wild-type Arabidopsis released phenolic compounds that are derived from $\mathrm{H}, \mathrm{G}$ and $\mathrm{S}$ lignin units, together with other compounds derived from carbohydrates. The predominant lignin-derived aromatic (phenolic) compounds were guaiacol (2), 4-methylguaiacol (5), 4vinylguaiacol (8), syringol (14), trans-isoeugenol (17), 4-methylsyringol (18), 4vinylsyringol (24) and trans-coniferaldehyde (38). The pyrolysis revealed a predominance of G- over S-lignin units, with an $\mathrm{S} / \mathrm{G}$ ratio of 0.35 . On the other hand, pyrolysis of the COMT-deficient Arabidopsis mutant released mostly phenolic compounds derived from G lignin units, such as guaiacol (2), 4-methylguaiacol (5), 4ethylguaiacol (7), 4-vinylguaiacol (8), trans-isoeugenol (17), trans-coniferyl alcohol (37) and trans-coniferaldehyde (38), with only traces of S-derived lignin units, resulting in an extremely low $\mathrm{S} / \mathrm{G}$ ratio of 0.01 . These results are produced because the enzyme COMT is directly involved in the biosynthesis of sinapyl alcohol, catalyzing the penultimate step that consists of the methylation of 5-hydroxyconiferaldehyde to sinapaldehyde before its reduction to sinapyl alcohol. Therefore, a strong downregulation of COMT activity leads to plants with lignin depleted in S-units, as already observed by 2D NMR spectroscopy [30,35]. In addition, Py-GC/MS data analysis shows that the relative abundances of the compounds derived from lignin and carbohydrates remained almost unchanged (L/C ratios: 0.93 for wild type $v s 0.91$ for comt mutant), which indicates that COMT downregulation mainly altered the lignin composition without significantly altering the lignin content. 
Another interesting aspect of COMT mutants is that they can incorporate 5hydroxyconiferyl alcohol into the lignin polymer giving rise to benzodioxane substructures that are readily detectable by NMR [30,36], derivatization followed by reductive cleavage method (DFRC) [37] and thioacidolysis [38]. The occurrence of lignins incorporating alternative monomers [30,39], usually derived from products of incomplete monolignol biosynthesis such as 5-hydroxyconiferyl alcohol, is another demonstration of the flexibility of the lignification process [40].

Influence of the pyrolysis system on the release of 5-hydroxyguaiacyl units from benzodioxane structures upon Py-GC/MS

The incorporation of 5-hydroxyconiferyl alcohol into the lignin polymer produces benzodioxane structures as a diagnostic feature of COMT-downregulated plants. These benzodioxane structures, under pyrolysis condition, should give rise to 5hydroxyguaiacyl compounds as already reported when a Curie-Point pyrolyzer was employed [41,42]. Surprisingly, however, but as has been noted in our labs and others previously, 5-hydroxyguaiacyl compounds were absent from our pyrograms that were obtained using a microfurnace pyrolyzer. Likewise, caffeyl alcohol-derived peaks were similarly difficult to find in pyrograms in OMT-deficient softwoods using another microfurnace pyrolyzer [29]. Numerous repetitions of the analyses under different pyrolysis conditions (using a wide range of pyrolysis temperatures from 400 to $600{ }^{\circ} \mathrm{C}$ and pyrolysis times from 15 to $120 \mathrm{~s}$ ) also failed to detect these compounds. However, it is important to note here that 5-hydroxyguaiacol can be readily detected using the Frontier microfurnace pyrolysis system used in this work, and that an authentic standard of 5-hydroxyguaiacol has been analyzed without any problem in this pyrolysis system. 
Hence, the absence of 5-hydroxyguaiacyl units upon pyrolysis of COMT-deficient Arabidopsis seems to indicate that the microfurnace pyrolyzer is not able to release such monomers from benzodioxane structures. Therefore, and in order to assess whether the pyrolysis system used is essential for the release of 5-hydroxyguaiacyl compounds from benzodioxane structures, this Arabidopsis comt mutant, together with another Arabidopsis mutant sample (comt C4H:F5H1 chs), generated by concomitant downregulation of comt and upregulation of $F 5 H$ using a $\mathrm{C} 4 \mathrm{H}$-promoter and characterized by an extremely high content of 5-hydroxyconiferyl alcohol involved in benzodioxane structures [30], was analyzed using a different Py-GC/MS system equipped with a Curie-Point pyrolyzer. Interestingly, and contrary to what occurred when using a microfurnace pyrolyzer, pyrolysis employing a Curie-point unit released significant amounts of 5-hydroxyguaiacol and related compounds, including the vinyland propenyl- counterparts, especially from the Arabidopsis comt C4H:F5H1 chs mutant. Figure 5 shows a comparison of the selected-ion chromatograms (SIM) of the main monomeric compounds (guaiacol, $\mathrm{m} / \mathrm{z}$ 124; 5-hydroxyguaiacol, $\mathrm{m} / \mathrm{z} 140$ and syringol, $m / z$ 154) obtained upon pyrolysis of Arabidopsis comt C4H:F5H1 chs mutant using microfurnace and Curie-Point pyrolysis systems. Hence, significant amounts of 5hydroxyguaiacol, arising from the cleavage of benzodioxane substructures, could only be released when a Curie-point system was used. This unequivocally reveals that the pyrolysis system employed is critical to release these compounds. Although H:G:S values 22:23:55 (Curie point system) and 21:21:58 (microfurnace pyrolyzer) can be derived as usual, the fact that potentially significant and diagnostic new components from these lignins, 5-hydroxyguaiacyl (5OHG) units, do not produce diagnostic monomers is an important limitation that should be taken into consideration when a microfurnace pyrolyzer is used. 


\subsection{Wild-type and C3H-deficient alfalfa}

The design of plants deficient in the enzyme $\mathrm{C} 3 \mathrm{H}$ has its origin in the search for plants with lower lignin content and higher degradability compared to wild type plants. $\mathrm{C} 3 \mathrm{H}$ is an enzyme that acts early in the biosynthesis of lignin monomers, catalyzing the incorporation of the hydroxyl group at the 3-position of $p$-coumarate to produce the caffeate, which is the first step in the biosynthesis of coniferyl alcohol and sinapyl alcohol (Figure 1). The pyrograms of the wild-type and $\mathrm{C} 3 \mathrm{H}$-downregulated alfalfa revealed striking differences between the S/G lignin in normal wild-type alfalfa vs the H-rich lignin in the $\mathrm{C} 3 \mathrm{H}$-downregulated plant (Figure 3, Table 1). Pyrolysis of the wild-type alfalfa released phenolic compounds derived from H-, G- and S-lignin units, with the most abundant pyrolysis products being guaiacol (2), 4-methylguaiacol (5), 4vinylguaiacol (8), syringol (14), trans-isoeugenol (17), 4-methylsyringol (18), 4vinylsiringol (24) and trans-4-propenylsyringol (31), with an H:G:S ratio of 8:54:38. Pyrolysis of the stems from $\mathrm{C} 3 \mathrm{H}$ deficient alfalfa released a completely different set of phenolic compounds that were mostly derived from $\mathrm{H}$-lignin units, including 4methylphenol (3), 3-methylphenol (4), 4-ethylphenol (6), 4-vinylphenol (9) and trans-4propenylphenol (16), with a striking H:G:S ratio of 71:18:11. As mentioned above, $\mathrm{C} 3 \mathrm{H}$ is an essential enzyme for the eventual formation of coniferyl and sinapyl alcohols, and thereby $\mathrm{C} 3 \mathrm{H}$ downregulation blocks the biosynthesis of both lignin precursors (Figure 1), keeping the $S / G$ ratio almost constant and producing extraordinarily high levels of H-units. A decrease in the relative abundance of lignin-derived compounds compared to those derived from carbohydrates (peaks a-f) was also observed in the pyrograms, as indicated by the decrease of the lignin/carbohydrate ratio from 2.4 in the wild-type alfalfa to 0.8 in the $\mathrm{C} 3 \mathrm{H}$ transgenic. These data are in agreement with previous studies, 
based on DFRC and 2D-NMR analysis, that reported an increase in H-lignin units in the $\mathrm{C} 3 \mathrm{H}$ transgenic and Klason lignin contents of $9.7 \%$ and $6.8 \%$ for wild-type and the C3H line, respectively [43].

\subsection{Wild-type and F5H-overexpressed poplar}

Another ingenious strategy to produce lignins more amenable to chemical degradation consists of reducing the level of condensed linkages and branch-points within the polymer. This can be achieved by increasing the proportion of S-lignin units, in which the aromatic 3- and 5-positions are methoxylated. S-lignin units result from the incorporation of sinapyl alcohol into the lignin polymer during the lignification process. Therefore, an increase in the proportion of sinapyl alcohol within the pool of monolignols would lead to lignin enriched in S-units that is less-branched and less recalcitrant for pulping and saccharification purposes [44]. Syringyl-rich lignins can be generated by the overexpression of the gene encoding the enzyme $\mathrm{F} 5 \mathrm{H}$, which is the responsible of the hydroxylation of coniferaldehyde to form 5-hydroxyconiferaldehyde that is subsequently reduced to sinapyl alcohol (Figure 1) $[8,45]$. The pyrograms from the stems of wild-type and $F 5 H$-overexpressed transgenic poplar are shown in Figure 4, and the identities and relative molar abundances of the main pyrolysis products are detailed in Table 1. The pyrolysis of wild-type poplar released mainly guaiacol (2), 4methylguaiacol (5), 4-vinylguaiacol (8), syringol (15), 4-methylsyringol (18), 4vinylsiringol (24), trans-propenylsyringol (31), syringaldehyde (33) and transsinapaldehyde (43), with a H:G:S composition of 2:26:67 and an S/G ratio of 2.63. In addition, some amounts of $p$-hydroxybenzoic acid (36), arising from $p$-hydroxybenzoate residues that acylate the $\gamma$-hydroxyl group of S-lignin units [46], were also released. A 
fraction of the $p$-hydroxybenzoates might decarboxylate upon pyrolysis producing phenol, in the same way as $p$-coumarates and ferulates decarboxylate generating 4vinylphenol and 4-vinylguaiacol. However, phenol may also be produced from polysaccharides [21], so we do not use the phenol peak for quantification of any of the $p$-hydroxyphenyl-derived products. The pyrogram from the poplar $F 5 H$-upregulated line was markedly different compared to that of the wild-type as the pyrolysis released overwhelming amounts of phenolic compounds derived from S-lignin units, whereas compounds derived from G-lignin units were released only in lower amounts. Consequently, the $F 5 H$ transgenic poplar presented an H:G:S composition of 3:9:88 with an extremely high $S / G$ ratio of 10.12. Prior NMR analyses [8] suggested that the $S$ level might be as high as $97.5 \%$ (with a corresponding $\mathrm{S} / \mathrm{G}$ of $\sim 40$ ); each method measures the components with different sensitivities and therefore the discrepancy is not of concern as both methods show the remarkable enhancement in the S-level in the transgenic. In addition, a decrease in the content of $p$-hydroxybenzoic acid (36) in $F 5 H$ upregulated compared to wild-type poplar was observed, in agreement with a previous study [8]. 


\section{Conclusions}

Py-GC/MS has proven to be a useful and convenient tool for the rapid evaluation of compositional changes in lignin from genetically modified plants. Small amount of samples $(<1 \mathrm{mg}$ ), short analysis time (less than $30 \mathrm{~min}$ ), and no tedious or timeconsuming isolation processes are required. In addition, the high sensitivity of PyGC/MS allows the in situ characterization of plants with relatively low lignin contents, such as in the $\mathrm{C} 3 \mathrm{H}$ alfalfa transgenic plant, with a lignin content as low as $6.8 \%$. PyGC/MS analyses indicated that the lignin of COMT-deficient Arabidopsis mutant is mostly composed of G-units, with an extremely low S/G ratio of 0.01 in comparison to that of the wild-type plant ( $\mathrm{S} / \mathrm{G} 0.35$ ). In addition, the data indicated that $\mathrm{C} 3 \mathrm{H}$-deficient alfalfa presented lower lignin content than the wild-type plant, and that was extremely enriched in $\mathrm{H}$-lignin units. Finally, pyrolysis of the $\mathrm{F} 5 \mathrm{H}$-overexpressed transgenic poplar indicated that its lignin is mostly made of S-units compared to the wild-type plant that also presented significant amounts of G-units. However, a major limitation exits for the release of 5-hydroxyguaiacyl units from benzodioxane structures in COMT-deficient plants, which seems to be highly dependent of the pyrolysis system used; virtually no traces of 5-hydroxyguaiacyl units could be detected with a microfurnace pyrolyzer but significant amounts were released when a Curie-point pyrolyzer was used. Nevertheless, the dramatic H:G:S shifts observed by Py-GC/MS imply that significant changes have occurred in the lignin composition. Py-GC/MS, therefore, has significant value as a rapid screening method.

\section{Acknowledgements}


This study has been funded by the Spanish projects CTQ2014-60764-JIN and AGL2014-53730-R (co-financed by FEDER funds), the CSIC project 2014-40E-097 and the EU-project INDOX (KBBE-2013-7-613549. John Ralph was funded through the DOE Great Lakes Bioenergy Research Center (DOE BER Office of Science DEFC02-07ER64494). We are grateful to various labs for samples that had been used in prior studies: WT alfalfa and $C 3 H$-downregulated transgenics [10] from R. A. Dixon, U. North Texas, USA; WT Arabidopsis and comt and comt C4H:F5H1 chs mutants from W. Boerjan, Ghent University, Belgium; and for WT and $F 5 H$-overexpressed high-S poplar [22] from S. Mansfield, UBC, Canada, and Clint Chapple, U. Purdue, USA. 


\section{References}

[1] R. Vanholme, K. Morreel, C. Darrah, P. Oyarce, J. Grabber, J. Ralph, W. Boerjan, Metabolic engineering of novel lignin in biomass crops, New Phytol. 196 (2012) 978-1000.

[2] J. Ralph, K. Lundquist, G. Brunow, F. Lu, H. Kim, P.F. Schatz, J.M. Marita, R.D. Hatfield, S.A. Ralph, J.H. Christensen, W. Boerjan, Lignins: natural polymers from oxidative coupling of 4-hydroxyphenylpropanoids, Phytochem. Rev. 3 (2004) 29-60.

[3] J.C. del Río, P. Prinsen, J. Rencoret, L. Nieto, J. Jiménez-Barbero, J. Ralph, Á.T. Martínez, A. Gutiérrez, Structural characterization of the lignin in the cortex and pith of Elephant grass (Pennisetum purpureum) stems, J. Agr. Food Chem. 60 (2012) 3619-3634.

[4] R. Vanholme, K. Morreel, J. Ralph, W. Boerjan, Lignin engineering, Curr. Opin. Plant Biol. 11 (2008) 278-285.

[5] R. Vanholme, K. Morreel, J. Ralph, W. Boerjan, Lignin biosynthesis and structure, Plant Physiol. 153 (2010) 895-905.

[6] J. Ralph, G. Brunow, P.J. Harris, R.A. Dixon, P.F. Schatz, W. Boerjan, Lignification: Are lignins biosynthesized via simple combinatorial chemistry or via proteinaceous control and template replication? in F. Daayf, A. El Hadrami, L. Adam, G.M. Ballance (Eds.), Recent Advances in Polyphenol Research, Vol 1, Wiley-Blackwell Publishing, Oxford, UK, 2008, pp. 36-66.

[7] S.K. Huntley, D. Ellis, M. Gilbert, C. Chapple, S.D. Mansfield, Significant increases in pulping efficiency in $\mathrm{C} 4 \mathrm{H}-\mathrm{F} 5 \mathrm{H}$-transformed poplars: Improved 
chemical savings and reduced environmental toxins, J. Agr. Food Chem. 51 (2003) 6178-6183.

[8] J.J. Stewart, T. Akiyama, C.C.S. Chapple, J. Ralph, S.D. Mansfield, The effects on lignin structure of overexpression of ferulate 5-hydroxylase in hybrid poplar, Plant Physiol. 150 (2009) 621-635.

[9] O. Skyba, C.J. Douglas, S.D. Mansfield, Syringyl-rich lignin renders poplars more resistant to degradation by wood decay fungi, Appl. Environ. Microbiol. 79 (2013) 2560-2571.

[10] M.S.S. Reddy, F. Chen, G.L. Shadle, L. Jackson, H. Aljoe, R.A. Dixon, Targeted down-regulation of cytochrome P450 enzymes for forage quality improvement in alfalfa (Medicago sativa L.), Proc. Natl. Acad. Sci.102 (2005) $16573-16578$.

[11] O. Faix, in Holzforschung - International Journal of the Biology, Chemistry, Physics and Technology of Wood, 1991, p. 21.

[12] J. Ralph and L.L. Landucci, NMR of Lignins, in C. Heitner, D.R. Dimmel, J.A. Schmidt (Eds.), Lignin and Lignans; Advances in Chemistry, CRC Press (Taylor \& Francis Group), Boca Raton, FL, 2010, pp. 137-234.

[13] M. Tanahashi, T. Higuchi, Chemical degradation methods for characterization of lignins, in Methods in Enzymology, Academic Press, 1988, pp. 101-109.

[14] Y. Xie, S. Yasuda, Difference of condensed lignin structures in eucalyptus species, Nordic Pulp Paper Res. J. 19 (2004) 18-21.

[15] C. Rolando, B. Monties, C. Lapierre, Thioacidolysis, in Methods in Lignin Chemistry, Springer Series in Wood Science, 1992, pp. 334-349. 
[16] F. Lu, J. Ralph, Derivatization followed by reductive cleavage (DFRC method), a new method for lignin analysis: protocol for analysis of DFRC monomers, J. Agr. Food Chem. 45 (1997) 2590-2592.

[17] J. Rencoret, A. Gutierrez, J.C. del Río, Lipid and lignin composition of woods from different eucalypt species, Holzforschung 61 (2007) 165-164.

[18] J.C. del Río, J. Rencoret, P. Prinsen, Á.T. Martínez, J. Ralph, A. Gutiérrez, Structural characterization of wheat straw lignin as revealed by analytical pyrolysis, 2D-NMR, and reductive cleavage methods, J. Agr. Food Chem. 60 (2012) 5922-5935.

[19] J.C. del Río, A. Gutierrez, A.T. Martinez, Identifying acetylated lignin units in non-wood fibers using pyrolysis-gas chromatography/mass spectrometry, Rapid Commun. Mass Spectrom. 18 (2004) 1181-1185.

[20] O. Faix, D. Meier, I. Fortmann, Thermal degradation products of wood, A collection of electron-impact (EI) mass spectra of monomeric lignin derived products, Holz Roh-Werkstoff 48 (1990) 351-354.

[21] J. Ralph, R.D. Hatfield, Pyrolysis-GC-MS characterization of forage materials, J. Agr. Food Chem. 39 (1991) 1426-1437.

[22] T. Ohra-aho, M. Tenkanen, T. Tamminen, Direct analysis of lignin and ligninlike components from softwood kraft pulp by Py-GC/MS techniques, J. Anal. Appl. Pyrol. 74 (2005) 123-128.

[23] K.-i. Kuroda, T. Ozawa, T. Ueno, Characterization of sago palm (Metroxylon sagu Rottb.) lignin by analytical pyrolysis. J. Agr. Food Chem. 49 (2001) 18401847. 
[24] D. Meier, I. Fortmann, J. Odermatt, O. Faix, Discrimination of genetically modified poplar clones by analytical pyrolysis-gas chromatography and principal component analysis, J. Anal. Appl. Pyrol. 74 (2005) 129-137.

[25] A. Wagner, Y. Tobimatsu, L. Phillips, H. Flint, B. Geddes, F. Lu, J. Ralph, Syringyl lignin production in conifers: Proof of concept in a Pine tracheary element system, Proc. Natl. Acad. Sci. 112 (2015) 6218-6223.

[26] A. Wagner, Y. Tobimatsu, G. Goeminne, L. Phillips, H. Flint, D. Steward, K. Torr, L. Donaldson, W. Boerjan, J. Ralph, Suppression of CCR impacts metabolite profile and cell wall composition in Pinus radiata tracheary elements, Plant Mol. Biol. 81 (2013) 105-117.

[27] A. Wagner, L. Donaldson, H. Kim, L. Phillips, H. Flint, D. Steward, K. Torr, G. Koch, U. Schmitt, J. Ralph, Suppression of 4-coumarate-CoA ligase in the coniferous gymnosperm Pinus radiata, Plant Physiol. 149 (2009) 370-383.

[28] A. Wagner, J. Ralph, T. Akiyama, H. Flint, L. Phillips, K.M. Torr, B. Nanayakkara, L. Te Kiri, Exploring lignification in conifers by silencing hydroxycinnamoyl-CoA:shikimate hydroxycinnamoyltransferase in Pinus radiata, Proc. Natl. Acad. Sci. 104 (2007) 11856-11861.

[29] A. Wagner, Y. Tobimatsu, L. Phillips, H. Flint, K. Torr, L. Donaldson, L. Pears, J. Ralph, CCoAOMT suppression modifies lignin composition in Pinus radiata, Plant J. 67 (2011) 119-129.

[30] R. Vanholme, J. Ralph, T. Akiyama, F. Lu, J. Rencoret Pazo, J. Christensen, A. Rohde, K. Morreel, R. DeRycke, H. Kim, B. Van Reusel, W. Boerjan, Engineering traditional monolignols out of lignins by concomitant up-regulation F5H1 and down-regulation of COMT in Arabidopsis, Plant J. 64 (2010) 885897. 
[31] M.S.S. Reddy, F. Chen, G. Shadle, L. Jackson, H. Aljoe, R.A. Dixon, Targeted down-regulation of cytochrome P450 enzymes for forage quality improvement in alfalfa (Medicago sativa L.), Proc. Natl. Acad. Sci. 102 (2005) 16573-16578.

[32] F. Chen, R.A. Dixon, Lignin modification improves fermentable sugar yields for biofuel production, Nature Biotechnol. 25 (2007) 759-761.

[33] Y. Barrière, C. Riboulet, V. Méchin, S. Maltese, M. Pichon, A. Cardinal, C. Lapierre, T. Lübberstedt, M. Jean-Pierre, Genetics and genomics of lignification in grass cell walls based on maize as model species, Gene, Genomes and Genomics 1 (2007) 133-156.

[34] L. Jouanin, T. Goujon, V. de Nadaï, M.-T. Martin, I. Mila, C. Vallet, B. Pollet, A. Yoshinaga, B. Chabbert, M. Petit-Conil, C. Lapierre, Lignification in transgenic poplars with extremely reduced caffeic acid $O$-methyltransferase activity, Plant Physiol. 123 (2000) 1363-1373.

[35] J.-K. Weng, H. Mo, C. Chapple, Over-expression of F5H in COMT-deficient Arabidopsis leads to enrichment of an unusual lignin and disruption of pollen wall formation, Plant J. 64 (2010) 898-911.

[36] J.M. Marita, J. Ralph, C. Lapierre, L. Jouanin, W. Boerjan, NMR characterization of lignins from transgenic poplars with suppressed caffeic acid O-methyltransferase activity, J. Chem. Soc., Perkin Trans. 1 (2001) 2939-2945.

[37] F. Lu, J.M. Marita, C. Lapierre, L. Jouanin, K. Morreel, W. Boerjan, J. Ralph, Sequencing around 5-hydroxyconiferyl alcohol-derived units in caffeic acid $O$ methyltransferase-deficient poplar lignins, Plant Physiol.153 (2010) 569-579.

[38] C. Lapierre, M.T. Tollier, B. Monties, A new type of constitutive unit in lignins from the corn $b m 3$ mutant, Comptes rendus de l'Académie des sciences, Série III, 307 (1988) 723-728. 
[39] J. Ralph, C. Lapierre, J. Marita, H. Kim, F. Lu, R.D. Hatfield, S.A. Ralph, C. Chapple, R. Franke, M.R. Hemm, J. Van Doorsselaere, R.R. Sederoff, D.M. O’Malley, J.T. Scott, J.J. MacKay, N. Yahiaoui, A.-M. Boudet, M. Pean, G. Pilate, L. Jouanin, W. Boerjan, Elucidation of new structures in lignins of CADand COMT-deficient plants by NMR, Phytochem. 57 (2001) 993-1003.

[40] C.G. Wilkerson, S.D. Mansfield, F. Lu, S. Withers, J.-Y. Park, S.D. Karlen, E. Gonzales-Vigil, D. Padmakshan, F. Unda, J. Rencoret, J. Ralph, Monolignol Ferulate Transferase introduces chemically labile linkages into the lignin backbone, Science 344 (2014) 90-93.

[41] J.C. del Río, Á.T. Martínez, A. Gutiérrez, Presence of 5-hydroxyguaiacyl units as native lignin constituents in plants as seen by Py-GC/MS, J. Anal. Appl. Pyrol. 79 (2007) 33-38.

[42] S. Suzuki, T.B.T. Lam, K. Iiyama, 5-Hydroxyguaiacyl nuclei as aromatic constituents of native lignin, Phytochem. 46 (1997) 695-700.

[43] J. Ralph, T. Akiyama, H. Kim, F. Lu, P.F. Schatz, J.M. Marita, S.A. Ralph, M.S.S. Reddy, F. Chen, R.A. Dixon, Effects of coumarate-3-hydroxylase downregulation on lignin structure, J. Biol. Chem. 281 (2006) 8843-8853.

[44] J.C. del Río, A. Gutiérrez Suárez, M. Hernando, P. Landín, Á.T. Martínez Ferrer, J. Romero Sánchez, Determining the influence of eucalypt lignin composition in paper pulp yield using Py-GC/MS, J. Anal. Appl. Pyrol. 115, (2005) 110-115.

[45] K. Meyer, A. Shirley, J. Cusumano, D. Bell-Lelong, C. Chapple, Lignin monomer composition is determined by the expression of a cytochrome P450dependent monooxygenase in Arabidopsis, Proc. Natl. Acad. Sci. 95 (1998) $6619-6623$. 
[46] F. Lu, S. Karlen, M. Regner, H. Kim, S. Ralph, R.-C. Sun, K.-i. Kuroda, M. Augustin, R. Mawson, H. Sabarez, T. Singh, G. Jimenez-Monteon, S. Zakaria, S. Hill, P. Harris, W. Boerjan, C. Wilkerson, S. Mansfield, J. Ralph, Naturally phydroxybenzoylated lignins in palms, Bioenergy Res. 8 (2015) 934-952. 


\section{FIGURE LEGENDS}

Figure 1. The main monolignol biosynthetic pathway including the enzymes and metabolites involved (adapted from Vanholme et al., 2010) [5]. PAL, phenylalanine ammonia lyase; $\mathrm{C} 4 \mathrm{H}$, cinnamate 4-Hydroxylase; 4CL, 4-coumarate:CoA ligase; HCT, hydroxycinnamoyl-CoA:shikimate/quinate hydroxycinnamoyltransferase; $\mathrm{C} 3 \mathrm{H}, \quad p$ coumarate 3-hydroxylase; CSE, caffeoyl shikimate esterase; CCoAOMT, caffeoyl-CoA $O$-methyltransferase; $\mathrm{F} 5 \mathrm{H}$, ferulate 5-hydroxylase; COMT, caffeic acid $O$ methyltransferase; CCR, cinnamoyl-CoA reductase; CAD, cinnamyl alcohol dehydrogenase. Only the steps that involve the enzymes $\mathrm{C} 3 \mathrm{H}$, COMT and $\mathrm{F} 5 \mathrm{H}$, involved in this study, are highlighted.

Figure 2. Pyrograms (Total-Ion Chromatograms) from stem of Arabidopsis wild-type (A) and COMT-deficient mutant (B), obtained using a Frontier 2020 pyrolyzer. The identities and relative abundances of the compounds released by Py-GC/MS are listed in Table 1. Carbohydrates peaks: furfural (a), 2,3 dihydro-5-methylfuran-2-one (b), (5H)furan-2-one (c), 2-hydroxy-3-methyl-2-cyclopenten-1-one (d), 5-hydroxymethyl-2furfuraldehyde (e) and levoglucosan (f).

Figure 3. Pyrograms (Total-Ion Chromatograms) of alfalfa stem material from wildtype (A) and a C3H-deficient transgenic (B), obtained using a Frontier 2020 pyrolyzer. The identities and relative abundances of the compounds released by Py-GC/MS are listed in Table 1. Carbohydrates peaks: furfural (a), 2,3 dihydro-5-methylfuran-2-one (b), (5H)-furan-2-one (c), 2-hydroxy-3-methyl-2-cyclopenten-1-one (d), 5hydroxymethyl-2-furfuraldehyde (e) and levoglucosan (f).

Figure 4. Pyrograms (Total-Ion Chromatograms) of hybrid poplar (Populus tremula $\mathrm{x}$ Populus alba) wild-type (A) and the $F 5 H$-upregulated transgenic (B), obtained using a 
Frontier 2020 pyrolyzer. The identities and relative abundances of the compounds released by Py-GC/MS are listed in Table 1. Carbohydrates peaks: furfural (a), 2,3 dihydro-5-methylfuran-2-one (b), (5H)-furan-2-one $\quad$ (c), 2-hydroxy-3-methyl-2cyclopenten-1-one (d), 5-hydroxymethyl-2-furfuraldehyde (e) and levoglucosan (f).

Figure 5. Comparative single ion chromatograms of the lignin monomers guaiacol $(\mathrm{m} / \mathrm{z}$ 124), 5-hydroxyguaiacol $(\mathrm{m} / \mathrm{z}, 140)$ and syringol $(\mathrm{m} / \mathrm{z}, 154)$ released from Arabidopsis comt C4H:F5H1 chs mutant upon pyrolysis using a Curie-Point pyrolyzer (A) and a microfurace pyrolyzer (B). The arrow indicates the retention time at which 5hydroxyguaiacol should elute according to a standard compound. 
Table 1. Identities and relative molar abundances of the lignin-derived compounds identified in the pyrograms, obtained using a microfurnace pyrolyzer, of the samples analyzed in the present work.

\begin{tabular}{|c|c|c|c|c|c|c|c|c|}
\hline $\mathrm{N}^{\mathrm{o}}$ & Compound & Origin $^{a}$ & $\begin{array}{c}\text { Arabidopsis } \\
\text { WT }\end{array}$ & $\begin{array}{c}\text { Arabidopsis } \\
\text { COMT }\end{array}$ & \begin{tabular}{|c} 
Alfalfa \\
WT
\end{tabular} & $\begin{array}{c}\text { Alfalfa } \\
\text { C3H }\end{array}$ & \begin{tabular}{|c} 
Poplar \\
WT
\end{tabular} & $\begin{array}{c}\text { Poplar } \\
\text { F5H } \\
\end{array}$ \\
\hline 1 & phenol & $\mathrm{LH} / \mathrm{C}$ & 2.7 & 3.7 & 3.5 & 25.0 & 1.8 & 3.2 \\
\hline 2 & guaiacol & LG & 10.7 & 15.8 & 11.3 & 4.8 & 4.8 & 1.8 \\
\hline 3 & 4-methylphenol & LH & 1.8 & 2.9 & 2.2 & 8.9 & 1.3 & 1.6 \\
\hline 4 & 3-methylphenol & LH & 4.8 & 6.8 & 4.6 & 25.8 & 0.7 & 1.7 \\
\hline 5 & 4-methylguaiacol & LG & 13.1 & 18.3 & 7.0 & 3.4 & 3.4 & 1.3 \\
\hline 6 & 4-ethylphenol & LH & 0.6 & 0.7 & 0.5 & 5.5 & 0.0 & 0.0 \\
\hline 7 & 4-ethylguaiacol & LG & 3.6 & 5.0 & 2.9 & 1.7 & 0.7 & 0.5 \\
\hline 8 & 4-vinylguaiacol & LG & 10.1 & 15.4 & 7.0 & 2.0 & 3.8 & 1.4 \\
\hline 9 & 4-vinylphenol & LH & 0.0 & 0.0 & 0.5 & 5.6 & 0.0 & 0.0 \\
\hline 10 & 4-allylphenol & LH & 0.0 & 0.0 & 0.0 & 0.6 & 0.0 & 0.0 \\
\hline 11 & eugenol & LG & 0.8 & 1.4 & 0.5 & 0.0 & 0.2 & 0.1 \\
\hline 12 & 4-propylguaiacol & LG & 0.9 & 1.3 & 0.5 & 0.2 & 0.2 & 0.1 \\
\hline 13 & cis-4-propenylphenol & $\mathrm{LH}$ & 0.0 & 0.0 & 0.0 & 0.7 & 0.0 & 0.0 \\
\hline 14 & syringol & LS & 3.4 & 0.2 & 5.7 & 1.6 & 9.1 & 10.1 \\
\hline 15 & cis-isoeugenol & LG & 1.4 & 2.0 & 1.1 & 0.2 & 0.3 & 0.1 \\
\hline 16 & trans-4-propenylphenol & $\mathrm{LH}$ & 0.0 & 0.0 & 0.0 & 4.1 & 0.0 & 0.0 \\
\hline 17 & trans-isoeugenol & LG & 5.3 & 7.3 & 4.2 & 1.0 & 2.1 & 1.0 \\
\hline 18 & 4-methylsyringol & LS & 4.5 & 0.3 & 5.4 & 0.7 & 5.4 & 5.5 \\
\hline 19 & vanillin & LG & 3.2 & 3.0 & 1.8 & 0.0 & 1.1 & 0.3 \\
\hline 20 & propyne-G & LG & 0.8 & 0.9 & 0.8 & 0.0 & 0.6 & 0.3 \\
\hline 21 & propyne-G & LG & 1.5 & 1.8 & 0.7 & 0.0 & 0.5 & 0.2 \\
\hline 22 & 4-ethylsyringol & LS & 0.5 & 0.0 & 1.2 & 0.5 & 1.2 & 1.4 \\
\hline 23 & acetovanillone & LG & 3.7 & 3.4 & 1.8 & 0.0 & 2.0 & 0.5 \\
\hline 24 & 4-vinylsyringol & LS & 4.0 & 0.5 & 6.8 & 2.0 & 12.7 & 14.5 \\
\hline 25 & guaiacylacetone & LG & 3.0 & 2.9 & 2.2 & 0.0 & 1.3 & 0.4 \\
\hline 26 & 4-allyl-syringol & LS & 0.4 & 0.0 & 0.7 & 0.2 & 1.4 & 2.1 \\
\hline 27 & propiovanillone & LG & 0.7 & 0.5 & 0.3 & 0.0 & 0.1 & 0.1 \\
\hline 28 & cis-4-propenylsyringol & LS & 0.5 & 0.0 & 0.7 & 0.2 & 1.2 & 1.5 \\
\hline 29 & propyne $S$ & LS & 0.0 & 0.0 & 1.0 & 0.0 & 2.3 & 2.6 \\
\hline 30 & propyne $S$ & LS & 0.0 & 0.0 & 0.7 & 0.0 & 1.3 & 1.6 \\
\hline 31 & trans-4-propenylsyringol & LS & 3.4 & 0.0 & 5.0 & 1.7 & 10.1 & 14.2 \\
\hline 32 & dihydroconiferyl alcohol & LG & 0.0 & 0.0 & 1.5 & 0.0 & 0.0 & 0.0 \\
\hline 33 & syringaldehyde & LS & 2.4 & 0.0 & 2.3 & 0.0 & 5.7 & 7.4 \\
\hline 34 & cis-coniferyl alcohol & LG & 0.0 & 0.0 & 1.1 & 0.0 & 0.0 & 0.0 \\
\hline 35 & 4-hydroxybenzoic acid & $\mathrm{PB}$ & 0.0 & 0.0 & 0.0 & 0.0 & 4.2 & 2.9 \\
\hline 36 & acetosyringone & LS & 1.7 & 0.0 & 1.8 & 0.4 & 3.3 & 5.2 \\
\hline 37 & trans-coniferyl alcohol & LG & 2.9 & 2.6 & 3.4 & 0.0 & 1.4 & 0.0 \\
\hline 38 & trans-coniferaldehyde & LG & 5.4 & 3.8 & 3.6 & 0.0 & 2.9 & 0.0 \\
\hline 39 & syringylacetone & LS & 1.5 & 0.0 & 1.8 & 0.5 & 3.2 & 4.5 \\
\hline 40 & propiosyringone & LS & 0.0 & 0.0 & 0.6 & 0.0 & 1.0 & 1.4 \\
\hline 41 & dihydrosinapyl alcohol & LS & 0.0 & 0.0 & 0.6 & 0.0 & 1.1 & 1.6 \\
\hline 42 & trans-sinapyl alcohol & LS & 0.0 & 0.0 & 0.4 & 0.0 & 0.9 & 1.1 \\
\hline 43 & trans-sinapaldehyde & LS & 1.1 & 0.0 & 2.2 & 0.0 & 7.0 & 7.8 \\
\hline \multicolumn{3}{|c|}{$\% \mathrm{H}^{\mathrm{b}}$} & 7.7 & 11.2 & 8.1 & 71.0 & 2.1 & 3.5 \\
\hline \multicolumn{3}{|c|}{$\% \mathrm{G}$} & 68.4 & 87.8 & 53.5 & 18.4 & 27.0 & 8.7 \\
\hline \multicolumn{3}{|c|}{$\% \mathrm{~S}$} & 23.9 & 1.1 & 38.4 & 10.6 & 70.9 & 87.8 \\
\hline \multicolumn{3}{|c|}{$\% \mathrm{~PB}^{\mathrm{c}}$} & - & - & - & - & 4.4 & 3.1 \\
\hline \multicolumn{3}{|c|}{ Syringyl/Guaiacyl ratio } & 0.3 & 0.0 & 0.7 & 0.6 & 2.63 & 10.12 \\
\hline \multicolumn{3}{|c|}{ Lignin/carbohydrate ratio $(\mathrm{L} / \mathrm{C})^{\mathrm{d}}$} & 0.9 & 0.9 & 2.4 & 0.8 & 2.0 & 3.4 \\
\hline \multicolumn{3}{|c|}{ Lignin content $(\%)^{\mathrm{e}}$} & 12.0 & 10.5 & 9.7 & 6.8 & 22.7 & 21.8 \\
\hline
\end{tabular}

${ }^{a}$ LH: H-lignin units, LG: G-lignin units, LS: S-lignin units, PB: $p$-hydroxybenzoates and C: carbohydrates. ${ }^{b}$ Phenol content has not been considered for calculation of $\% \mathrm{H}$ because it could also be derived carbohydrates under pyrolysis conditions. ${ }^{c} \% \mathrm{~PB}$ is expressed as a fraction of $(\mathrm{S}+\mathrm{G}+\mathrm{H}) .{ }^{\mathrm{d}}$ Obtained using the molar areas of the carbohydrates peaks a-f (see figures 2-4). ${ }^{\mathrm{e}}$ From references 8,10 and 30. 